\title{
Head circumference during infancy in a birth cohort of Sri Lankan children: are we using the correct chart?
}

\author{
P J Perera1, M P Fernando', R Samaranayake ${ }^{2}$
}

\begin{abstract}
Introduction Measuring head circumference and plotting it in centile charts is a routine practice in paediatrics. However if wrong charts are used, serious misinterpretations can ensue.

Objectives This study was carried out to ascertain the appropriateness of charts used in Sri Lanka. Out of a birth cohort of 2215 children, 250 from each sex were invited for a follow up study. Head circumference was measured at 2, 4, 6, 9 and 12 months. Statistical charac-teristics of head circumference for each sex, at each age were calculated.

Results At the first follow up 244 boys and 241 girls were assessed. Out of this, $85 \%$ of boys and $86 \%$ of girls completed the follow up.

Conclusions Head circumference of both sexes deviated significantly at all ages from the charts available in the Child Health Developmental Record (CHDR). Head circumference charts available in the CHDR are inappropriate for use in Sri Lankan children.
\end{abstract}

Ceylon Medical Journal 2014; 59: 136-138

\section{Introduction}

In normal children increase in head circumference (HC) parallels brain growth. Reduced brain growth causes slow or absent increase in $\mathrm{HC}$, while intracranial expansive lesions cause a rapid increase. Therefore by monitoring $\mathrm{HC}$, a child with these problems can be detected early. According to a Norwegian study, in $46 \%$ of children with intracranial expansive conditions, increased $\mathrm{HC}$ was the first and main symptom [1].

Meaningful HC monitoring depends on the availability of appropriate reference charts. It was our observation that majority of Sri Lankan children are placed on lower centiles, according to $\mathrm{HC}$ charts available in the Child Health Development Record (CHDR), which is used in Sri Lanka [2]. This study was conducted to ascertain the appropriateness of CHDR charts for interpreting HC of Sri Lankan children.

\section{Methods}

Gampaha district has a population over two million, which consists of $12 \%$ of the Sri Lankan population
[3]. In 2002 Gampaha district had only $9.2 \%$ of poor house-holds. Other than Colombo and Gampaha districts, the percentages of poor households are $>15 \%$ in other districts [4].

A previous study conducted in September 2012, assessed growth parameters at birth of babies born in the Gampaha District [5]. All normal term babies $(n=2215)$, born within the district during a one month period were recruited for that study. Out of these, a follow up study was conducted with 250 babies from each sex, between November 2012 and October 2013. Each baby in the original study was assigned a number, and babies were randomly selected for the study using computer generated numbers. Assuming less than $40 \%$ of our children have $\mathrm{HC} \geq 50$ th centile of the CHDR charts, a sample size of 114 was required to estimate this to within $9 \%$. As assessing factors influencing $\mathrm{HC}$ was also an objective of this study, calculated sample size was doubled. Parents of selected babies were informed about the study via telephone or post. Babies were followed up at two, four, six, nine and twelve months. A special clinic was conducted at the University Paediatric Unit of North Colombo Teaching Hospital for follow up of the participants. Participation in the study was voluntary.

$\mathrm{HC}$ of children was measured by a medical graduate. To avoid inter-observer error, the same medical graduate took the measurement in all children at all ages. The medical graduate had one week training under the principal investigator. Measurements were randomly repeated by the principal investigator. Intra-class correlation coefficient of 0.97 was obtained between the two sets of observations.

At each visit babies were also examined by a consultant Paediatrician or a Senior Registrar in Paediatrics. Medical problems detected at follow up visits were treated. Next visit date was informed to the parents and reminders were sent via telephone or post. Children who missed a scheduled clinic were given a new appointment during the same week. Children who defaulted were not followed up further.

Descriptive statistics were generated using Statistical Package for Social Sciences, version 16. Centiles were calculated for $\mathrm{HC}$ according to age and sex. Data from dropped outs were compared with children who completed

\section{${ }^{1}$ Department of Paediatrics and ${ }^{2}$ Tropical Medicine and International Health Unit, Faculty of Medicine, University of Kelaniya, Sri Lanka.}

Correspondence: PJP, e-mail: <priyanthaprr@gmail.com>. Received 27 March 2014 and revised version accepted 30 July 2014. Competing interests: none declared. 
the study, to ascertain the impact of drop outs on the final analysis.

Approval was obtained from the Ethics Committee of Faculty of Medicine, Ragama. Informed written consent was obtained from mothers at first visit. Apart from travelling expenses, there were no additional expenses to the parents. Parents had the right to withdraw their child from the study at any stage.

\section{Results}

Sample consisted of 250 babies from each sex. At the two month follow up, 244 boys and 241 girls were assessed. Out of this $85 \%$ of boys and $86 \%$ of girls completed the study. Table 1 shows the numbers examined at each age. The study sample was from a reasonably good socio-economic background. Table 2 shows maternal education and monthly family income of babies who completed the study.

At all ages, HC of both sexes showed a normal

Table 1. Number of babies examined at each time point

\begin{tabular}{llllll}
\hline Sex & 2 & 4 & 6 & 9 & One \\
& months & months & months & months & year \\
\hline Male & 244 & 232 & 226 & 217 & 208 \\
Female & 241 & 230 & 228 & 219 & 209 \\
\hline
\end{tabular}

Table 2. Socio-demographic characteristics of the babies followed up till one year of age

\begin{tabular}{lc}
\hline \multicolumn{1}{c}{ Characteristic } & Number $(\%)$ \\
\hline Maternal education & \\
0 -5 years & $8(1.9)$ \\
6 -11 years & $234(56.1)$ \\
12-14 years & $153(36.7)$ \\
University Education & $22(5.3)$ \\
& \\
Monthly family income (SLR) & \\
$<5,000$ & $3(0.7)$ \\
$5001-10,000$ & $35(8.4)$ \\
$10,001-15,000$ & $149(35.7)$ \\
$15,001-30,000$ & $155(37.2)$ \\
$30,001-50,000$ & $40(9.6)$ \\
$>50,000$ & $35(8.4)$ \\
\hline
\end{tabular}

$1 \mathrm{US} \$=110 \mathrm{SLR}$

distribution. At all ages, in both sexes, mean HC of the study population was between the 10 th and 25 th centile according to CHDR and only $20-24 \%$ had a $\mathrm{HC} \geq 50$ th centile. Statistical characteristics of $\mathrm{HC}$ for boys and girls are depicted in tables 3 and 4. For comparison relevant figures from the CHDR are also given. At all ages, in both sexes, mean values of CHDR charts were outside the 95\% confidence interval of the study population (Table 5). No significant difference was observed between the data from children who dropped out and children who completed the study.

Table 3. Mean head circumference in boys at different ages: comparison with CHDR data

\begin{tabular}{|c|c|c|c|c|c|}
\hline & $\begin{array}{c}2 \\
\text { months }\end{array}$ & $\begin{array}{c}4 \\
\text { months }\end{array}$ & $\begin{array}{c}6 \\
\text { months }\end{array}$ & $\begin{array}{c}9 \\
\text { months }\end{array}$ & $\begin{array}{c}12 \\
\text { months }\end{array}$ \\
\hline \multicolumn{6}{|l|}{ 5th centile } \\
\hline This study $(\mathrm{cm})$ & 37.0 & 39.0 & 40.4 & 42.0 & 43.4 \\
\hline$C H D R(\mathrm{~cm})$ & 37.2 & 39.8 & 41.4 & 43.0 & 44.3 \\
\hline \multicolumn{6}{|l|}{ 10th centile } \\
\hline This study $(\mathrm{cm})$ & 37.1 & 39.5 & 41.0 & 42.5 & 44.0 \\
\hline$C H D R(\mathrm{~cm})$ & 37.5 & 40.3 & 41.8 & 43.5 & 44.6 \\
\hline \multicolumn{6}{|l|}{ 25th centile } \\
\hline This study $(\mathrm{cm})$ & 37.9 & 40.1 & 41.7 & 43.3 & 44.5 \\
\hline$C H D R(\mathrm{~cm})$ & 38.8 & 41.1 & 42.7 & 44.3 & 45.4 \\
\hline \multicolumn{6}{|l|}{ 50th centile } \\
\hline This study $(\mathrm{cm})$ & 38.5 & 41.0 & 42.5 & 44.1 & 45.3 \\
\hline$C H D R(\mathrm{~cm})$ & 40.0 & 42.0 & 43.6 & 45.1 & 46.2 \\
\hline \multicolumn{6}{|l|}{ 75th centile } \\
\hline This study $(\mathrm{cm})$ & 39.5 & 41.8 & 43.0 & 45.0 & 46.0 \\
\hline$C H D R(\mathrm{~cm})$ & 40.8 & 43.0 & 44.5 & 46.0 & 47.1 \\
\hline \multicolumn{6}{|l|}{ 90th centile } \\
\hline This study $(\mathrm{cm})$ & 40.0 & 42.3 & 44.0 & 45.5 & 47.0 \\
\hline$C H D R(\mathrm{~cm})$ & 41.6 & 43.8 & 45.3 & 46.8 & 47.9 \\
\hline \multicolumn{6}{|l|}{ 95th centile } \\
\hline This study $(\mathrm{cm})$ & 40.5 & 43.0 & 44.5 & 46.0 & 47.5 \\
\hline$C H D R(\mathrm{~cm})$ & 42.1 & 44.4 & 45.8 & 47.3 & 48.4 \\
\hline
\end{tabular}

Table 4. Mean head circumference in girls at different ages: comparison with CHDR data

\begin{tabular}{lccccc}
\hline & 2 & 4 & 6 & 9 & 12 \\
& months & $\begin{array}{c}\text { months } \\
\text { months }\end{array}$ & $\begin{array}{c}\text { months } \\
\text { months }\end{array}$ \\
\hline 5th centile & & & & & \\
This study (cm) & 36.0 & 38.2 & 40.1 & 41.5 & 42.2 \\
CHDR (cm) & 36.4 & 38.9 & 40.4 & 41.7 & 42.8 \\
10th centile & & & & & \\
This study (cm) & 36.5 & 39.0 & 40.3 & 41.9 & 43.0 \\
CHDR (cm) & 36.8 & 39.3 & 40.8 & 42.2 & 43.4 \\
25th centile & & & & & \\
This study (cm) & 37.2 & 35.5 & 41.0 & 42.5 & 43.6 \\
CHDR (cm) & 37.8 & 40.1 & 41.5 & 42.9 & 44.0 \\
50th centile & & & & & \\
This study (cm) & 37.7 & 40.1 & 41.5 & 43.0 & 44.1 \\
CHDR (cm) & 38.8 & 40.8 & 42.3 & 43.8 & 44.9 \\
75th centile & & & & & \\
This study (cm) & 38.4 & 41.0 & 42.1 & 43.7 & 44.8 \\
CHDR (cm) & 39.8 & 41.8 & 43.2 & 44.6 & 45.8 \\
90th centile & & & & & \\
This study (cm) & 39.2 & 41.5 & 43.0 & 44.3 & 45.5 \\
CHDR (cm) & 40.6 & 42.6 & 44.1 & 45.5 & 46.6 \\
95th centile & & & & & \\
This study (cm) & 39.8 & 42.5 & 43.6 & 44.9 & 46.2 \\
CHDR (cm) & 41.3 & 43.2 & 44.6 & 46.0 & 47.2 \\
\hline & & & & &
\end{tabular}


Table 5. Means and $95 \%$ confidence intervals of study sample compared with CHDR means at different ages for boys and girls

\begin{tabular}{|c|c|c|c|c|c|c|}
\hline \multirow[b]{2}{*}{ Age } & \multicolumn{3}{|c|}{ Boys } & \multicolumn{3}{|c|}{ Girls } \\
\hline & CHDR Mean & Our mean & $95 \% C I$ & CHDR Mean & Our Mean & $95 \% C I$ \\
\hline 2 months & 40.0 & 38.5 & $38.4-38.7$ & 38.7 & 37.7 & $37.6-37.9$ \\
\hline 4 months & 42.2 & 41.0 & $40.7-41.1$ & 40.8 & 40.1 & $40.0-40.3$ \\
\hline 6 months & 43.7 & 42.5 & $42.2-42.6$ & 42.3 & 41.5 & $41.5-41.7$ \\
\hline 9 months & 45.2 & 44.1 & $43.9-44.1$ & 43.8 & 43.0 & $42.9-43.1$ \\
\hline 1 year & 46.3 & 45.3 & $45.2-45.6$ & 44.9 & 44.1 & $44.0-44.3$ \\
\hline
\end{tabular}

\section{Discussion}

Conventionally growth charts are prepared from data of children with maximum growth potentials. HC charts available in the CHDR are based on World Health Organisation, Multicentre Growth Reference Study (MGRS). MGRS included only children with maximum growth potentials [6]. Our study population also included only normal, term, singleton babies, born both in private and government hospitals and had no conditions adversely affecting their brain growth. As the study population was from a reasonably good socio-economic background, we can assume our study population consisted of a sample of Sri Lankan children with good growth potential.

As the results indicate, $\mathrm{HC}$ charts in the CHDR overestimates the HC of Sri Lankan children. This means some children who are normal will be subjected to unnecessary follow up and investigations, while some children who need interventions will be missed. If we consider boys in the study at two months, according to CHDR $10 \%$ of the children are placed below the 5th centile, but only $4 \%$ are below the 5 th centile according to our data. If children with $\mathrm{HC}$ less than 5 th centile are investigated, $6 \%$ of children will undergo unnecessary investigations. This places an unnecessary burden on our health system. Similarly if the cut off point for a large HC is set above the 95 th centile, $3 \%$ of children according to study data need further follow up, but according to CHDR charts none need follow up. Therefore, a child with a large head according to Sri Lankan standards will not be detected until HC has increased significantly. This will delay early interventions aimed at minimising disability.

Unlike weight and length, routine $\mathrm{HC}$ monitoring is not done at Well-baby clinics. HC is measured by a medical officer only when there are concerns about it [2]. This questionable practice further stresses the importance of having $\mathrm{HC}$ charts appropriate for our population. If serial recordings are made, it would be easy to pick up children with lower or higher $\mathrm{HC}$ growth, as the child will be crossing centile lines. When a single reading is interpreted with an inappropriate chart, a child with early changes in $\mathrm{HC}$ growth is likely to be missed.

It is not clear why children in our study had a lower $\mathrm{HC}$ growth in comparison to CHDR charts. As growth parameters of Sri Lankan children at birth were also shown to be significantly low compared to MGRS in three previous studies, genetic influence may be a possible explanation $[5,7,8$,$] . The main limitation in our study was$ the drop outs during the study.

\section{Conclusions}

$\mathrm{HC}$ of the study population was lower compared to charts in CHDR for both sexes at all ages during infancy. Therefore, $\mathrm{HC}$ charts available in CHDR may not be appropriate for use among Sri Lankan children. A national study to develop HC charts for Sri Lankan children is indicated.

\section{References}

1. Zahl SM, Wester K. Routine Measurement of Head Circumference as a Tool for Detecting Intracranial Expansion in Infants: What Is the Gain? A Nationwide Survey. Pediatrics 2008; 121: e416 -e420.

2. Ministry of Health, Sri Lanka. Child Health Developmental Record 2012.

3. Department of Disaster Management, Government of Sri Lanka. 2012. Available from http://www.dmc.gov.lk/ DistrictSection/Gampaha/Gampaha_P6DivisionalInfo. html

4. Department of Census and Statistics. Poverty Statistics/ Indicators for Sri Lanka. Colombo, Sri Lanka. 2002.

5. Perera PJ, Ranathunga N, Fernando M P, Warnakulasuriya T. Growth parameters at birth of babies born in Gampaha district, Sri Lanka and factors influencing them. WHO South-East Asia Journal of Public Health 2013; 2: 49-54.

6. de Onis M, Onayongo A, Broeck J, Chumlee C, Matorell R. Measurement and standardization protocols for anthropometry used in the construction of a new international growth reference. Food Nutrition Bulletin 2004; 25: S15-26.

7. Perera T, Lwin KM. Perinatal mortality and morbidity including low birth weight: A South-East Asia regional profile. New Delhi: WHO-SEARO,1984. SEARO Regional Health Papers No. 3.

8. Abeysena C, Payawardana P, Senevirathne R. Maternal sleep deprivation is a risk factor for small for gestational age: A cohort study. Australian and New Zeeland Journal of Obstetrics and Gynecology 2009; 49: 382-7. 